\title{
Development and validation of a novel process model for fluidized bed combustion: Application for efficient combustion of low-grade coal
}

Ablay Saparov ${ }^{1}$, Lyazzat Kulmukanova ${ }^{1}$, Ehsan Mostafavi ${ }^{1}$, Yerbol Sarbassov ${ }^{1,2}$, Vassilis Inglezakis ${ }^{1}$, Edward J Anthony ${ }^{3}$, and Dhawal Shah ${ }^{1 *}$

${ }^{1}$ Deparment of Chemical and Materials Engineering, School of Engineering and Digital Sciences, Nazarbayev University, Nur-Sultan, Kazakhstan.

${ }^{2}$ Green Energy and Environment Laboratory, National Laboratory Astana, Nazarbayev University, Kazakhstan

${ }^{3}$ Department of Chemical and Biological Engineering, University of Ottawa, Ottawa, Canada;

*Corresponding author: dhawal.shah@,nu.edu.kz

Keywords: Circulating Fluidized Bed Reactor (CFBR); Coal Combustion; Low-grade coal; Sensitivity Analyzed Optimization; Aspen Plus; Process Simulation. 
Acronyms

ASTM American Society for Testing and Materials

CFBR Circulating Fluidized Bed Reactor

FTIR Fourier-transform infrared spectroscopy

IEA International Energy Agency

NC Non-conventional

NCPSD Non-conventional Particle Solid Distribution

PC Pulverized Coal

PP Power Plant

PSD Particle Size distribution

TDH Transport Disengagement Height

$\mathrm{U}_{\mathrm{mf}} \quad$ Minimum fluidization velocity 


\section{ABSTRACT}

Numerous models have been developed in Aspen Plus for the combustion of different coal types in fluidized bed reactors. However, these models are case-specific, particularly with respect to coal type and bed reactor type, implying limitations to general application of these models. Moreover, these processes were generally developed step-wisely by employing a series of model blocks to simulate fluidized bed reactors in Aspen Plus. In this study, a novel hybrid approach for modelling coal combustion has been implemented to comprehensively design a model for conversion of low-grade coal under various operating conditions. The proposed model combines sequential modeling of drying/pyrolysis (devolatilization) and combustion of coal by means of conventionally used units (RYIELD and RGIBBS), \& a newly used unit (FLUIDBED) in Aspen Plus. The model validation was performed by experiments on the combustion of low-grade coal in a pilot-scale circulating fluidized bed reactor (CFBR). Experimental data were used to further calibrate the Aspen Plus model and decrease model uncertainties. The results obtained from the developed simulation model were found to be in good agreement with the experimental data. Discrepancies of less than $15 \%$ were observed, in most of the predictions of molar fractions for the resultant flue gas composition, including $\mathrm{NO}_{\mathrm{x}} \& \mathrm{SO}_{\mathrm{x}}$, emissions which were at ppm levels. As a result, the model can easily be used for design, scale-up, and simulation of coal combustion as well as for other feedstock like biomass in fluidized bed with process optimization based on sensitivity analysis. 


\section{INTRODUCTION}

As a result of the accelerated economic growth in Asian countries, the International Energy Agency (IEA) projects nearly 50\% increase in world energy consumption by 2050 [1]. This increase in the global energy consumption, and its associated impact on the environment, has become one of the most debated issues. While renewable energy is important, combustion of different fuels such as coal, crude oil, and gas are likely to remain to be a common source of energy for the upcoming decades. Moreover, almost half of the world's electricity, and a quarter of the primary energy demand, is still provided by combustion of coal [2]. Approximately $4 \%$ of the world's coal reserves are located in Kazakhstan, which suggests that coal consumption will still continue to remain as one of the dominant source of energy supply in this country for the foreseeable future [3]. According to World Coal Association, Kazakhstan was ranked amongst top 10 coal producers in 2016 [4]. At present, the combustion of medium and high ash content bituminous coals typically occurs using pulverized-coal boilers (PC) for electricity and district heating [5]. More than half of the total electricity in Kazakhstan is produced by the combustion of high ash coal in thermal power plants, and moreover such plants are highly inefficient due to the use of old technologies and lack of investment [6]. For example, two major power plants (PP) located at the coal basins Ekibastuz-1 and Ekibastuz-2 with capacities of 1000 and 4000 MW, respectively, are the main electricity source for the region. Although old, they operate to provide electricity and also to manage deficit. Moreover, the aging technology used by Kazakhstani coal-fired power plants translates to low thermal efficiencies [4][6]. While the above information is case-specific to Kazakhstan, the situation is similar in several developing countries. The process and economics of coal combustion is further complicated with increasing constraints from various national and international institutions and regulations set on the emissions of $\mathrm{SO}_{\mathrm{x}}, \mathrm{NO}_{\mathrm{x}}$, particulate matter, and other pollutant emissions. 
The above-mentioned considerations provide encouragement to develop thermal processes further and explore ways to minimize pollution [7]. Circulating fluidized bed reactors (CFBRs) is an alternative technology for the conversion of low-grade solid fuels at relatively low temperatures, and typically has lower $\mathrm{SO}_{\mathrm{x}}$ and $\mathrm{NO}_{\mathrm{x}}$ emissions. Moreover, CFBRs can also utilize a variety of feedstock without major modifications, i.e. they are fuel flexible [8] . Over the last two decades, several models for CFBRs have been developed, at times, using specialized process simulation tools, to understand them and to optimize their operating conditions [7], [9]-[13]. Most of these models are based on the commercial Aspen Plus process modeling software, owing to its accuracy and reliability. For example, Dong et al. [14] described the modeling of the coal combustion in a circulated fluidized bed boiler. They used series of different reactors available in Aspen Plus to simulate the fluidized bed reactor unit such as RYield for decomposition, RGibbs for Gibbs equilibrium, cyclones, and heat exchangers. Their model was based on the following assumptions, which are commonly used in the literature $[8,11,12]$ : (a) the process is isothermal and steady state, (b) coal is decomposed into its constituent components as hydrogen, nitrogen, oxygen, water, sulfur, and char, which consists of fully reactive carbon and inert ash [12]. However, bed hydrodynamics was neglected in their model. Chen et al. [15] recently modeled a $50 \mathrm{~kW}$ CFBR using computational fluid-particle dynamics and validated the model with experimental results on flue gas concentrations. These authors later proposed optimized conditions for using chemical looping combustion of coal. However, this model is highly specific to the type of the coal and conditions studied, and did not adequately consider bed hydrodynamics. Hydrodynamic parameters affect the conversion of coal in CFBR and hence, both hydrodynamic and reaction kinetics must be treated simultaneously. In this regard, earlier, Nikoo and Mahinpey [16] modeled biomass gasification in fluidized bed reactor using Aspen Plus. Their model consisted of three steps: biomass decomposition, devolatilization, and the char gasification. The gasification reaction included both bubbling fluidized bed 
hydrodynamics parameters and kinetic parameters for coal combustion. However, the version of Aspen Plus, available at that time, did not have the necessary libraries to support bed hydrodynamics modelling and hence the authors modeled hydrodynamics separately using FORTRAN subroutines [14]. This model was validated using the lab-scale pine gasifier and the authors determined the effect of varying temperature on the reactivity of the carbon and hydrogen. Likewise, Nayak and Mewada [17] and Jurado et al. [18] modeled coal gasification via Aspen Plus using a series of RYield, RGibbs, RStoic reactors and performed analysis on oxycombustion and co-firing of coal and biomass mixtures. Using their model, which was validated with the experimental data obtained from a pilot-scale pulverized coal combustor [18], these authors pointed out that the heat flux during the oxy-combustion was three times higher than in conventional air-based combustion. While several such efforts have been made to model coal combustion in CFBR with varying models, most of them employ Aspen Plus and, case-specific FORTRAN subroutines [19]. Over time, Aspen Plus has become a recommended method for dealing with the solid handling processes owing to its strong solid databanks as well as its superior capabilities for determining solid characteristics (such as PSD) together with Property Methods for a wide range of solid fuel compounds. While Aspen plus offers flexibility in modeling, the subroutines that have been employed in the literature are specific to a given process, coal and bed type, and the governing equations used, thereby reducing the flexibility of the overall model for other applications.

A FLUIDBED unit has been available since version 8 of Aspen Plus and is an obvious choice to model CFBR. The unit includes a variety of governing equations for the incorporation of reactor hydrodynamics along with kinetics and the heat and mass balances. However, it has never been used for design of combustion process due to several modeling related issues. The purpose of this work is to develop a comprehensive and, at the same time, flexible model for combustion of coal in the CFBR, using the built-in FLUIDBED unit by Aspen Plus (version 11). 
In order to develop the foundation (building blocks/skeleton) for the model, we herein retrieve the kinetic equations of combustion reactions from the literature, while the geometric parameters for the fluidized bed reactor are based on the pilot-plant unit located at Nazarbayev University, Kazakhstan. It should be noted that although the model is currently designed for the low-quality Ekibastuz coal, it is flexible enough to accommodate combustion of any solid feedstock such as coal, biomass, or any combination of them. The kinetic-based (non-equilibrium) approach in the model for the dominant combustion reactions allows for more accurate prediction of composition profile along the height of the reactor over a wider span of operational conditions. This approach makes the model suitable for conceptual design, sizing, dynamics, and hence, scale up, feasibility study and techno-economic and environmental impact assessment. In what follows, we present the properties of the coal used in the experiments, highlighting the problems associated with its low quality. Then the details of the pilot-scale rig, along with its schematic diagram and dimensions are discussed. Next, the developed model is discussed and the results from the model are compared with those from the pilot-scale experiments. Finally, sensitivity analysis is reported to help identify the effects of various combustion parameters.

\section{METHODOLOGY}

\subsection{EXPERIMENTAL}

Coal analysis: The proximate and ultimate analyses of the bituminous coal are given in Table 1. The proximate analysis were performed determined to the ASTM standard [20], while the ultimate analysis was determined by CHNS elemental analyzer (vario MICRO cube Elementar, Germany). An important note here is that the available Ekibastuz coal has relatively high volatiles $(21.55 \%)$, but low sulfur $(0.6 \%)$ and low moisture content $(1.31 \%)$. The ash content of the coal is $38.24 \%$, indicating its poor quality. Using the bomb calorimeter, the heating value of the Ekibastuz coal was measured to be $19.4 \mathrm{MJ} / \mathrm{kg}$. 
Table 1: Proximate and ultimate analysis of the Ekibastuz coal.

\begin{tabular}{cc|cc}
\hline Proximate analysis (wt \%, as received) & \multicolumn{3}{|c}{ Ultimate analysis (wt \%, dry ash free) } \\
\hline Moisture & 1.31 & Ash & 38.24 \\
Fixed carbon & 40.21 & Carbon & 48.10 \\
Volatile matter & 21.55 & Hydrogen & 3.10 \\
Ash & 38.24 & Nitrogen & 1.40 \\
Calorific value & $19.4(\mathrm{MJ} / \mathrm{kg})$ & Sulfur & 0.60 \\
& & Oxygen $^{*}$ (by difference) & 8.56 \\
\hline
\end{tabular}

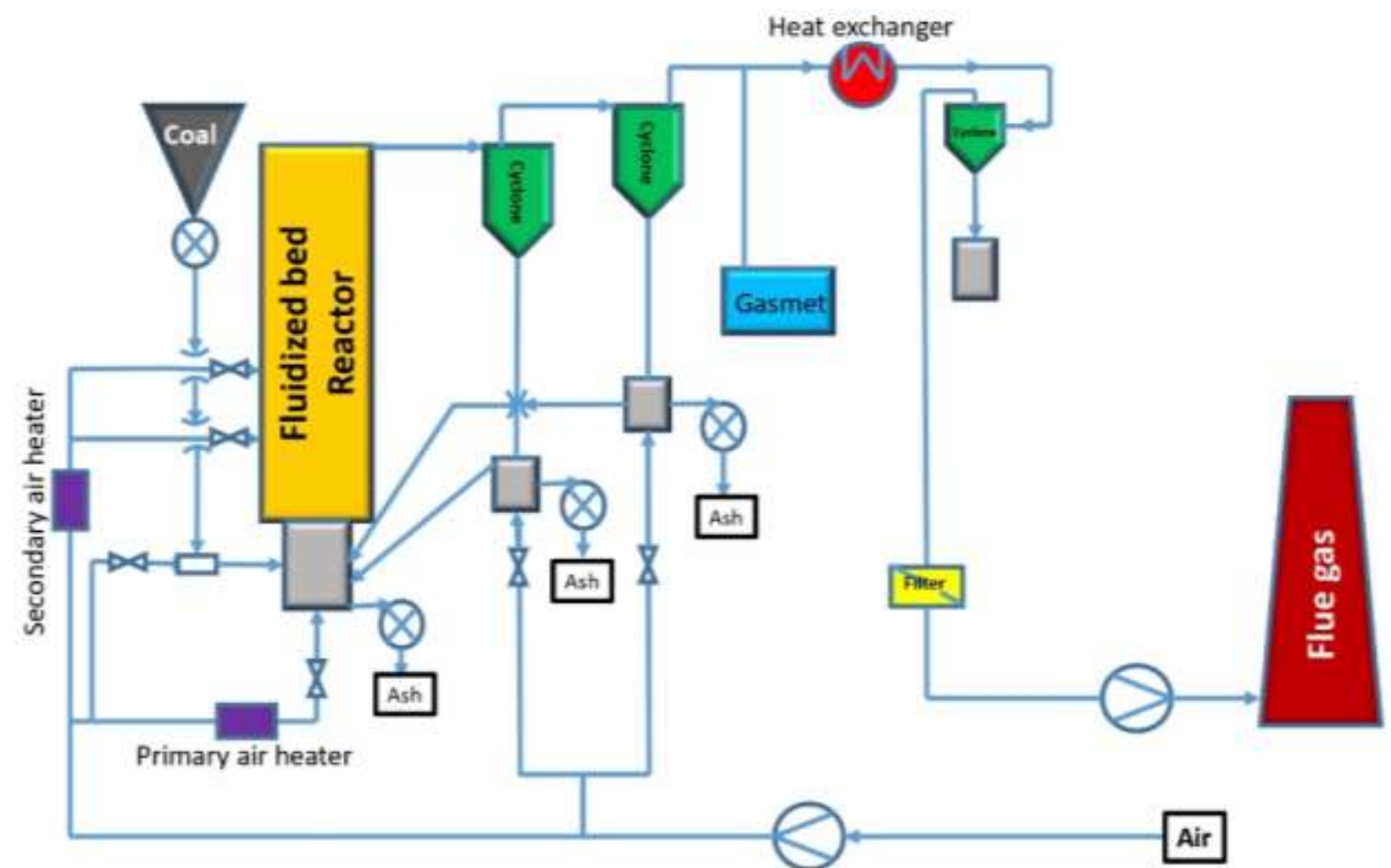

Figure 1: A scheme of the pilot-scale circulating fluidized bed unit.

Design of the Pilot-scale CFBR: The design of the pilot-scale CFBR, along with the auxiliary equipment, developed at Nazarbayev University, is shown schematically in Figure 1. The CFBR unit consists of air blower, primary air heater, tubular riser made of stainless-steel tube with an internal diameter of $180 \mathrm{~mm}$, cyclone separators, N-type loop seal, and fuel bunker. The total air flow rate was split into primary, secondary, and pneumatic flow for coal transportation. Pre- 
heated primary air was supplied from the bottom of the CFBR by means of an air blower. Sand particles with a mean particle size of $0.2 \mathrm{~mm}$ were used as bed material to maintain a uniform fluidization regime. Gas distributor composed of eight bubble-cap type, each with four openings that provided circumferential distribution of air. The operational details of the CFBR are presented later with the modeling section and are the same for the pilot-plant and those for the developed model. The dimensions of the designed CFBR are given in Table 2.

Table 2: Dimensions of the pilot-scale CFBR.

\begin{tabular}{cc}
\hline Fluidized bed reactor parameters \\
\hline Height & $7.0 \mathrm{~m}$ \\
Cross section type & Circular \\
Diameter & $180 \mathrm{~mm}$ \\
Bed mass & $7 \mathrm{~kg}$ \\
\hline
\end{tabular}

The flow rate of coal was maintained at $19 \mathrm{~kg} / \mathrm{h}$ which corresponds to the thermal capacity of around $\sim 100 \mathrm{~kW}$. The composition of the flue gas in the pilot plant was recorded using the calibrated FTIR spectroscopy gas analyzer (Gasmet Dx 4100). The tests were repeated three times in the pilot plant unit to ensure the repeatability of the results. During three different runs, the concentration of the $\mathrm{CO}_{2}$ was recorded to be within $12-15 \%$ for the particular air and coal flow rates. Concentrations for oxygen and water were from 3.5 to $5.0 \%$ and about $5 \%$, respectively. The $\mathrm{N}_{2} \mathrm{O}, \mathrm{NO}_{2}$, and $\mathrm{SO}_{2}$ concentrations were in the range of 80-120 ppm, 190-210 ppm, and 350-450 ppm, respectively. As the ash was collected cumulatively at the end of the experiments, the mass flow rate of the ash was assumed to be $\sim 9 \mathrm{~kg} / \mathrm{h}$ (based on the proximate analysis of the coal).

\subsection{MODELING/PROCESS SIMULATION}

In order to model fluidized bed coal combustion in Aspen Plus v11 the featured fluidized bed model (FLUIDBED) was employed for the first time. The coal processing application 
property method was used in Aspen with conventional, non-conventional, and mixed stream types, and Redlich-Kwong-Soave equation of state with Boston-Mathias modifications. APV90 ASPEN-BM and APV90 EOS-LIT databanks were used for binary interaction parameters in the particular model. Next, the reactions and kinetics parameters were set, details of which are discussed later along with the process design. The following assumptions were made during the process modeling: combustion process is assumed to be steady state; attrition of coal particles is neglected; heat losses are not considered; drying and pyrolysis processes are assumed to occur instantaneously; and pyrolysis results in full conversion of coal to elemental components; drying, pyrolysis, and combustion are assumed to be isothermal; tar undergoes complete thermal cracking and hence is neglected in the process development; ash is treated as inert throughout the process; and gas-solid separation occurred at $10 \%$ efficiency.

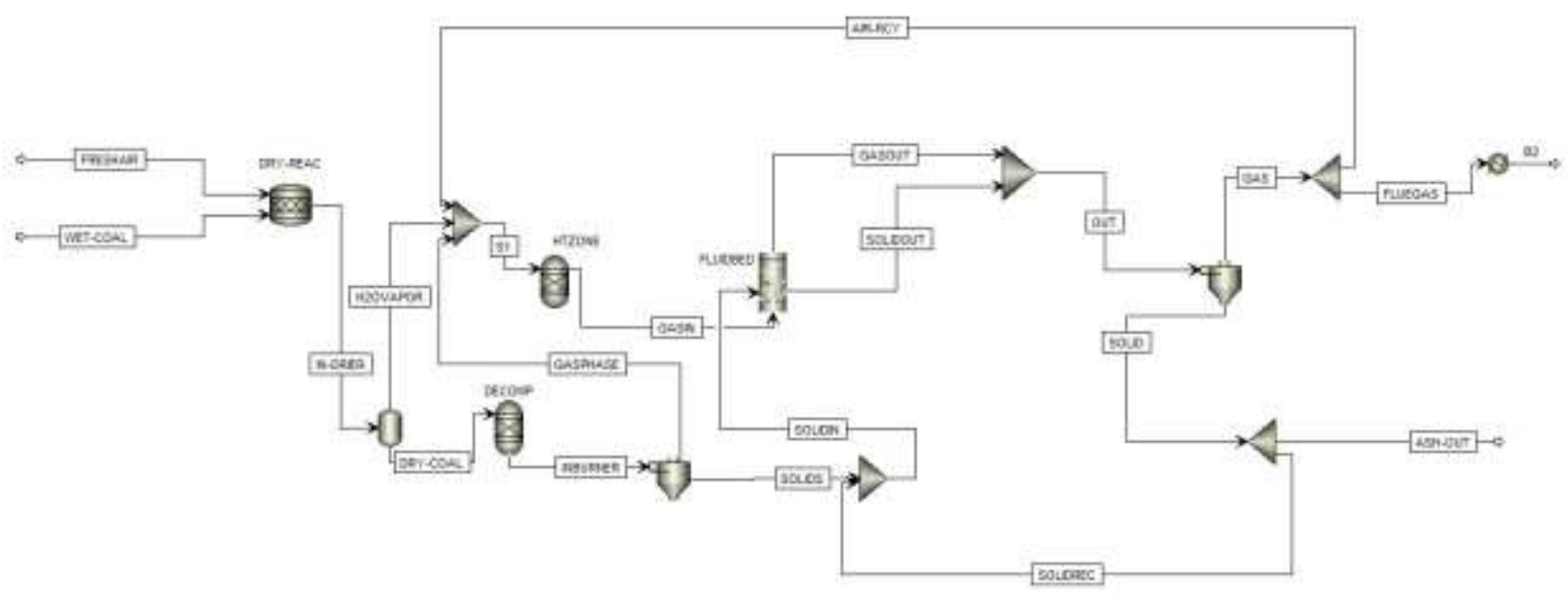

Figure 2: Aspen Plus flowsheet developed using FLUIDBED model for combustion of coal in CFBR.

Figure 2 shows the process flowsheet developed using the FLUIDBED model for combustion of coal in CFBR. A stream of wet coal was defined as a nonconventional (NC) substream of solids. Particle size distribution (PSD) was defined in the nonconventional sub-stream so as to make it a Non-Conventional Particle Size Distribution (NCPSD) class of solids. A GGS 
(Gates-Gaudin-Schuhmann) distribution function was chosen, with $8 \mathrm{~mm}$ as the maximum diameter and a dispersion parameter of 0.35 to mimic the experimental PSD of the wet coal. This assumption was made for the dense zone (coal particles) in the fluidization of the bed material. The GGS function used resulted in the average diameter of $4 \mathrm{~mm}$ with a particle size range of 0 $8 \mathrm{~mm}$ and a fine particle (particles smaller than $1 \mathrm{~mm}$ in diameter) mass fraction of $0.4-0.47$.

The approach presented here is different from the typical empirical and CFD methods and it allows extensive flexibility in changing the process parameters and conditions. FLUIDBED is a grey box model that utilizes semi empirical correlations for a one-dimensional ( $\mathrm{Z}$ or height) profile calculation along the height of the reactor. The governing equations and boundary condition are only set on the $\mathrm{z}$ axis and the other directions in the coordinates are assumed to be lumped. The hydrodynamic equations are based on the well-known studies done by George and Grace [21], Wen and Yu [22], Tasirin and Geldart [23], as per the latest Aspen tutorials. These studies have also been widely used in CFD studies (both in validation and advanced simulation). The scope of this current work, however; is not a 2-D or 3-D simulation with computational fluid dynamics techniques. Our study is centered on determining reaction kinetics and equilibrium in the combustion of coal rather than on hydrodynamics, hence hydrodynamics only indirectly this modelling process.

The combustion process on its own was separated into three phenomenological stages, namely drying, pyrolysis, and oxidation. RSTOIC unit operation was employed for the drying process and was considered as a conversion-type reactor, separating moisture content of the coal based on the equation given below [24].

$$
\text { wet coal } \rightarrow 0.0555084 \mathrm{H}_{2} \mathrm{O}+\text { dry coal }
$$

Following the RSTOIC, an RYIELD block was utilized to decompose the dried coal into its constituents, including gaseous products of $\mathrm{H}_{2}, \mathrm{H}_{2} \mathrm{O}, \mathrm{N}_{2}, \mathrm{~S}$, and $\mathrm{O}_{2}$, and solid products such as 
ash and carbon (char). Tar, because of its small amount was not included in the model. Next, the nonconventional component, ASH was used, which was considered to be inert throughout the process. Solid carbon was then routed to the main FLUIDBED unit as the solid phase, while other components were maintained in the gas phase with excess air as oxidizing/fluidizing agent in the respective CFBR from the bottom. The CFBR operational parameters are presented in Table 3. It is worth noting that although the experiments were performed at 1.5 to 2 bar(abs), the simulation model was set to 2 bar(abs) to ensure secondary air flow to the system.

Table 3: Operational parameters for the CFBR (FLUIDBED Model).

\begin{tabular}{ccc}
\hline Parameter & Value & Unit \\
\hline Coal Mass flow rate & 19 & $\mathrm{~kg} / \mathrm{h}$ \\
Coal Inlet Temperature & 20 & ${ }^{\circ} \mathrm{C}$ \\
Coal Inlet Pressure & 2 & $\mathrm{bar}$ \\
Fresh air flow rate & 100 & $\mathrm{~m}^{3} / \mathrm{h}$ \\
Air pressure & 2 & $\mathrm{bar}$ \\
Air temperature & 500 & ${ }^{\circ} \mathrm{C}$ \\
\hline
\end{tabular}

The voidage of bed material was identified at minimum fluidization velocity of $0.5 \mathrm{~m} / \mathrm{s}$ and Geldart type B classification was specified. The minimum fluidization velocity $\left(\mathrm{U}_{\mathrm{mf}}\right)$ was estimated using the Wen and Yu correlation [22]. The correlation is given below, where $d_{p}$ is the particle diameter, $\rho_{f}$ is fluid density, $\rho_{s}$ is particle density, and $\mu$ is fluid viscosity.

$$
U_{m f}=\frac{\left(\sqrt{(33.7)^{2}+0.0408 \times \frac{d_{p}^{3} \rho_{f}\left(\rho_{s}-\rho_{f}\right) g}{\mu^{2}}}-33.7\right) \mu}{d_{p} \rho_{f}}
$$

The George and Grace's model was applied for transport disengagement height $\left(\mathrm{TDH} ;=18.2 \mathrm{~d}_{\mathrm{b}}\right.$; where $d_{b}$ is the bubble diameter at the surface of the bottom zone) estimation, along with Tasirin and Geldart's model [23] for elutriation evaluation. The temperature of the isothermal reactor was set at $900{ }^{\circ} \mathrm{C}$. 
Table 4: Reaction parameters used in the simulations

\begin{tabular}{clll}
\hline$\#$ & \multicolumn{1}{c}{ Reactions } & \multicolumn{2}{c}{ Reaction rate constants } \\
\hline$(1)$ & $2 \mathrm{C}_{(\mathrm{s})}+\mathrm{O}_{2} \rightarrow 2 \mathrm{CO}$ & $\mathrm{k}_{1}=4.34 \times 10^{7} \mathrm{Texp}(-13519 / \mathrm{T})$ & {$[25],[26]$} \\
$(2)$ & $\mathrm{CO}+0.5 \mathrm{O}_{2} \rightarrow \mathrm{CO}_{2}$ & $\mathrm{k}_{2}=3.25 \times 10^{7} \exp (-15098 / \mathrm{T})$ & {$[27],[28]$} \\
$(3)$ & $\mathrm{H}_{2}+0.5 \mathrm{O}_{2} \rightarrow \mathrm{H}_{2} \mathrm{O}$ & $\mathrm{K}_{3}=1.14 \times 10^{12} \mathrm{~T}^{-1.5} \exp (-3430 / \mathrm{T})$ & {$[28],[29]$} \\
\hline
\end{tabular}

Three dominant chemical reactions were introduced in the fluidized bed reactor as shown in Table 4. Mass transfer resistances (including inter particle (within pores of each particle), intra particle (in between particles), and gas film mass transfer resistances) were not considered; however, they were indirectly taken into account for reactions 1 and 2 . This was accomplished by using the tuning parameters, Reaction Activity Factor. In essence, this activity factors incorporates the different behavior of reactions in the event that there is a reaction set rather than isolated reaction happening alone. These activity factors take into account multi-component mass transfers and reactivity of the main solid reactants (carbon) compared to the other reactions, as well as interactions among the reactions. Reaction 3 was excluded from this rule because it is not restricted, nor limited, and happens solely in the pores or at the surface of solids and thus intra-particle, inter-particle, and surface mass transfer resistances are absent. In addition, the model predictions for the third reaction matched the experimental data without using the tuning parameters [30]. It should be noted that LHHW \& Eley-Riedel [31] types of reaction rate laws were avoided here to separate out the kinetics and mass transfer calculations.

The oxidation reactions of the sulfur and nitrogen compounds in fuel were defined as equilibrium reactions based on the minimization of Gibbs free energy as is often done in the literature [32]-[34]. Convergence of the reaction was obtained by the Newton solver with an external Jacobian update method, in each iteration, by using a Dogleg stabilization strategy. The cyclones were designed according to the Modified Leith-Licht design method with Swift-GP type parameters. Table 5 provides a summary of the each of the major block used for the process 
development. The maximum number of iterations in all unit operations was selected to be 100 with 0.001 error tolerance.

Table 5: Summary of each of the module with input parameters used for the process development.

\begin{tabular}{|c|c|c|}
\hline Sub-process & Applied module & Input variable \\
\hline Drying & RStoic & $\begin{array}{l}\text { Pressure: } 1 \text { bar } \\
\text { Heat duty: } 0 \mathrm{~W} \\
\text { Eliminates moisture from coal }\end{array}$ \\
\hline Decomposition & RYield & $\begin{array}{l}\text { Temperature: } 900{ }^{\circ} \mathrm{C} \\
\text { Pressure: } 2 \text { bar } \\
\text { Decomposes coal into chemical components } \\
\text { using the calculator block }\end{array}$ \\
\hline Combustion of $\mathrm{C}$ and $\mathrm{H}_{2}$ & FLUIDBED & $\begin{array}{l}\text { Temperature: } 900{ }^{\circ} \mathrm{C} \\
\text { Bubble caps gas distributors } \\
\text { Geometry of the reactor (see Table 2) } \\
\text { Chemical reactions (see Table 4) }\end{array}$ \\
\hline Combustion of $\mathrm{N}_{2}$ and $\mathrm{S}$ & RGibbs & $\begin{array}{l}\text { Temperature: } 900{ }^{\circ} \mathrm{C} \\
\text { Restrict chemical equilibrium } \\
\text { Only } \mathrm{N}_{2} \text { and } \mathrm{S} \text { participate in the reactions }\end{array}$ \\
\hline Separation of ash and flue gas & Cyclone & $\begin{array}{l}\text { Modified Leith-Licht } \\
\text { Swift-GP } \\
\text { Splits solid and vapor phase after combustion }\end{array}$ \\
\hline
\end{tabular}

\section{RESULTS AND DISCUSSION}

\subsection{Validation of the Aspen Plus Model}

The primary purpose of the work was to develop consistent simulation model for the combustion of coal in a circulating fluidized bed reactor. The new FLUIDBED unit was used along with the kinetic reactions. The reactor conditions and operating parameters were based on the pilot-scale plant. The validation of the model was achieved by comparing emission results with the experimental value. The detailed results on mass and energy balance for each stream is shown in supplementary Table S1. Supplementary Figure S1, further, shows the process model with temperatures and pressure for all streams. The results on emission of gases from the model and experiments (see Table 6) show that the values predicted from the simulations are within $10 \%$ of the experiments, which supports the applicability of the model. Specific attention was focused 
the concentrations of $\mathrm{N}_{2} \mathrm{O}, \mathrm{NO}_{2}$, and $\mathrm{SO}_{2}$, as the formation of these gases are characterized by complex chemistry which is not easily described by simply considering the ultimate analysis of the feed flow [34]. The calculated concentration of $\mathrm{N}_{2} \mathrm{O}, \mathrm{NO}_{2}$, and $\mathrm{SO}_{2}$ in the flue gas were 71 ppm, 194 ppm, and 360 ppm, which are within the experimentally determined range. The other significant flue gases were also within the experimental range. The $\mathrm{CO}_{2}$ concentration was $11.9 \%$, which is within the experimental range of $12-15 \% . \mathrm{O}_{2}$ and $\mathrm{H}_{2} \mathrm{O}$ concentration from the model was $4.7 \%$ and $3.8 \%$, respectively, in comparison to the experimental values of $3.5-5 \%$ and $4-6 \%$, respectively. Furthermore, as would be expected, the ash flow rate $(9.7 \mathrm{~kg} / \mathrm{h})$, treated as inert in the process, was consistent with the experiments as well.

Table 6: Comparison between the experimental data and model results.

\begin{tabular}{ccc}
\hline Component & Experiment & Simulation \\
\hline $\mathrm{CO}_{2}$ & $12-15 \%$ & $11.9 \%$ \\
$\mathrm{O}_{2}$ & $3.5-5 \%$ & $4.7 \%$ \\
$\mathrm{H}_{2} \mathrm{O}$ & $4-6 \%$ & $3.8 \%$ \\
$\mathrm{~N}_{2} \mathrm{O}$ & $80-120 \mathrm{ppm}$ & $71 \mathrm{ppm}$ \\
$\mathrm{NO}_{2}$ & $190-210 \mathrm{ppm}$ & $194 \mathrm{ppm}$ \\
$\mathrm{SO}_{2}$ & $350-450 \mathrm{ppm}$ & $360 \mathrm{ppm}$ \\
Ash flow rate & $9 \mathrm{~kg} / \mathrm{h}$ & $9.7 \mathrm{~kg} / \mathrm{h}$ \\
\hline
\end{tabular}

Furthermore, according to the predictions of the simulation in this study for the fluidized bed reactor (combustor), the height of the bottom zone was $2.63 \mathrm{~m}$, the height of the freeboard was $2.86 \mathrm{~m}$ and the transport disengagement height (as illustrated in supplementary material Figure S2), as computed from the correlation was $3.28 \mathrm{~m}$, whereas transport disengagement height based on the solids volume fraction was $1.43 \mathrm{~m}$. The FLUIDBED model in Aspen Plus accounts for two zones along the height of the fluidized-bed reactor: dense bed (or bottom zone with high solids concentration) and Freeboard (with comparably low solids concentration). Additional hydrodynamics profile including superficial velocity, interstitial velocity, and pressure along with the height of the reactor are reported in supplementary Table S2 and S3. A major difference between the experimental and modeling flow sheet is that after the formation of 
the gaseous and solid products a cyclone separator was used in the model to separate the two phases. Gas phase from the cyclone, consisting of flue gases, is partially recycled back [35] to the fluidized bed reactor to ensure fluidization, with controlled oxidation while in the experiments, flue gases are not recycled. A recycle of flue gas (constituting of $25 \%$ of gases only) was introduced to ensure the convergence of the model, hence and does not qualitatively affect the results.

\subsection{Sensitivity analysis}

The sensitivity analyses were performed by varying coal flow rate, fresh air flow rate, combustion temperature, reactor height, and solids recycle, taking into account the influence on the flue gas composition. The range of each parameter for the sensitivity analysis was selected by considering the convergence of the whole system, excepting the elutriation cases. The observed variable was changed for each sensitivity analysis, while keeping CFBR dimensions as in Table 2 and other operating conditions as in Table 3 constant.

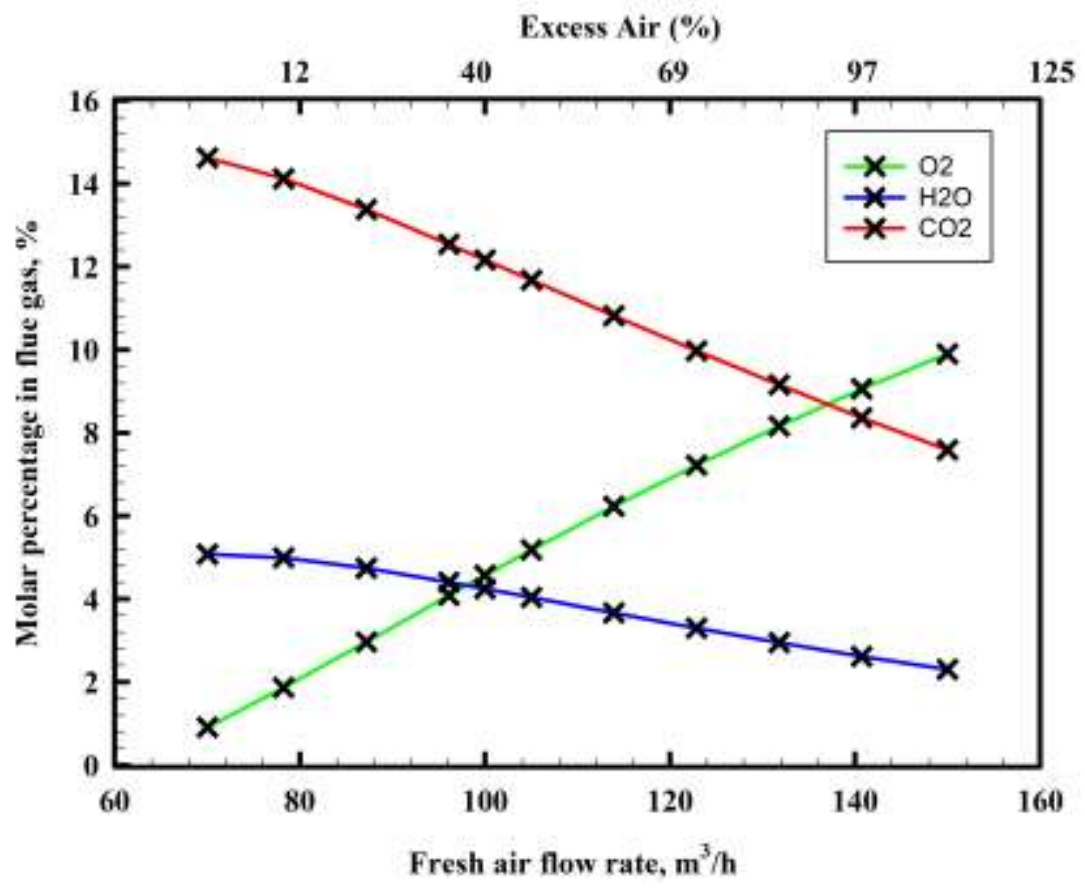

Figure 3: Effect of fresh air flow rate (and \% excess air) on flue gas composition $\left(\mathrm{O}_{2}, \mathrm{CO}_{2}\right.$ and $\left.\mathrm{H}_{2} \mathrm{O}\right)$. 
Figure 3 shows the influence of the airflow rate on the composition of the flue gas. The sensitivity analysis shows that excess oxygen level increases with the increase of the airflow rate indicating the unreacted volumes of oxygen. $\mathrm{CO}_{2}$ and water molar percentage decreases with increasing fresh air flowrate, as carbon and hydrogen, which are the limiting reagents, are fully reacted, and the overall flow rate increases. The pattern as shown in the Figure 4A-D illustrates components' concentration in the flue gas by varying the coal flow rate, combustion temperature, solids purge percentage, and reactor height, respectively. The concentration of $\mathrm{CO}_{2}$ and $\mathrm{H}_{2} \mathrm{O}$ increases with increasing coal flow rates. An increase of carbon conversion could be justified as reaching a reasonable stoichiometric condition by changing the flow rate of coal and maintaining $\mathrm{O}_{2}$ concentrations at around $3-4 \%$. These trends are consistent with the reaction kinetics. $\mathrm{CO}_{2}$ concentration decreases with purging more solids (consisting of ash and unreacted carbon) out rather than recycling it back. The oxygen concentration, on the other hand shows a significant drop in the case of increasing coal flow rates and temperature, because of its higher consumption in the reactions (reactions 1-3 of Table 4). The oxygen concentration also increases with more ash being purged from the system, preventing the consumption of oxygen in the reaction with unreacted carbon in ash. The water content increases marginally with higher coal flow rate, because of the hydrogen content in the coal. In addition, moisture from the wet coal also adds into the $\mathrm{H}_{2} \mathrm{O}$ content in the flue gas. Lastly, no significant change in the flue gas composition by varying the reactor height was observed, indicating that the reactor's height was sufficient for the particular conversion process and this seems optimal from the design perspective. It was also observed that the recirculating residual solid (unburned or unconverted carbon and ash mineral matters) act as a heat carrier to improve the mass and heat transfer along the reactor, via distributing heat [36]. 

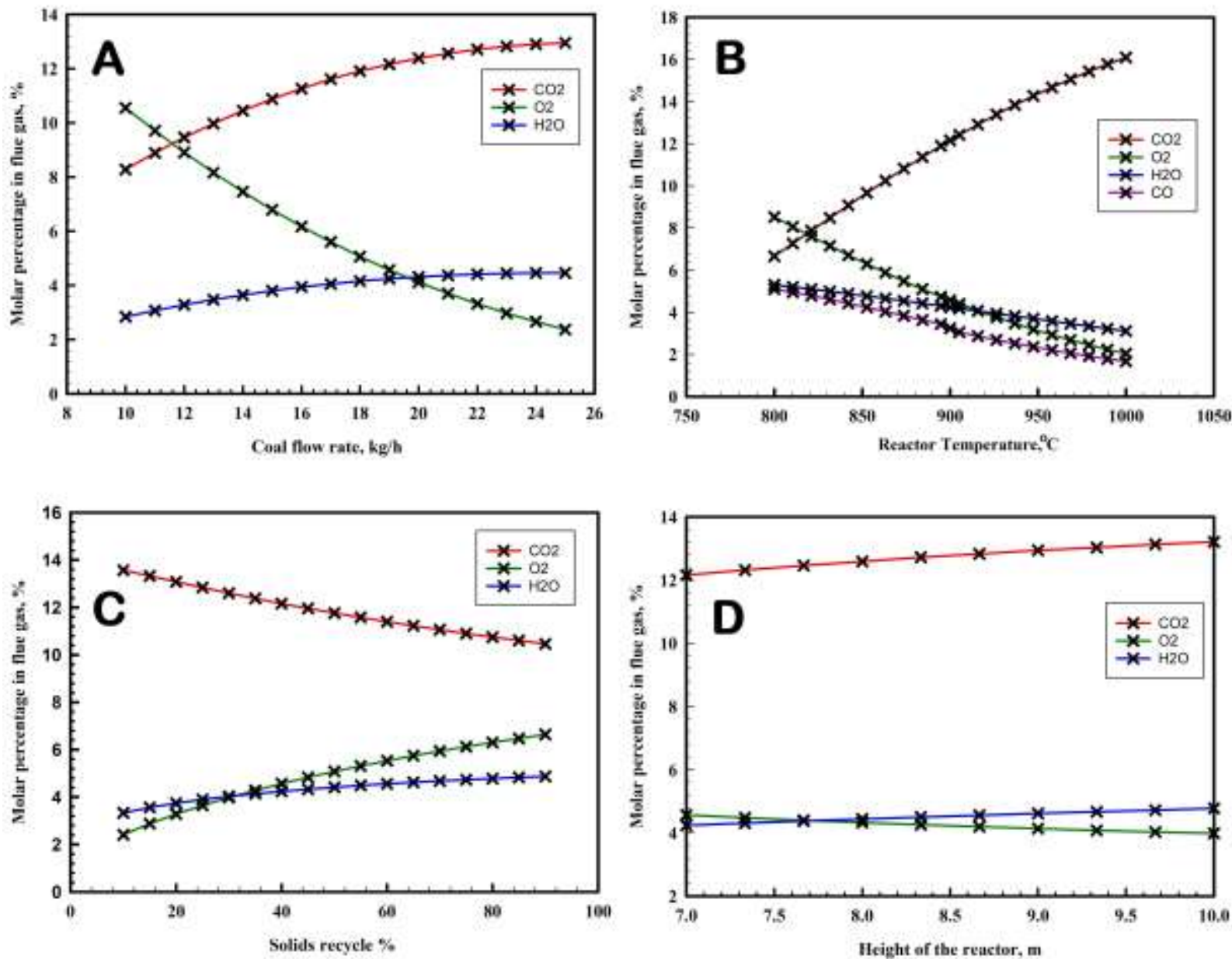

Figure 4: Variation in flue gas composition by changing (A) coal flow rate (B) temperature of the fluidized-bed (C) recycle of the solids and (D) height of the reactor.
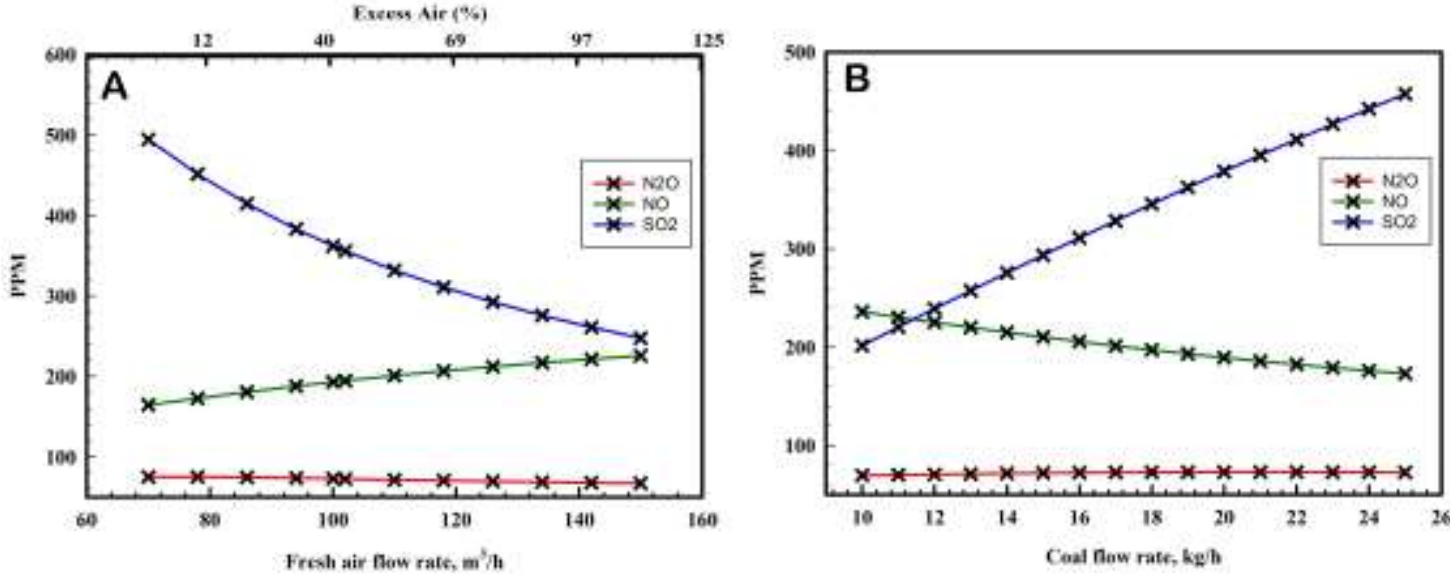

Figure 5: Effect of (A) fresh air flow rate and (B) coal flow rate on $\mathrm{N}_{2} \mathrm{O}, \mathrm{NO}_{2}$, and $\mathrm{SO}_{2}$ concentrations in flue gas. 
The increase of the fresh air flow rate leads to a slight increase of the $\mathrm{NO}_{2}$ formation, while decreasing $\mathrm{SO}_{2}$ as the coal flow rate remains constant (Figure 5A). As the reactor is isothermally controlled and temperature is constant at $900{ }^{\circ} \mathrm{C}$, the only reason for such behavior is due to the competition of $\mathrm{NO}_{2}$ and $\mathrm{SO}_{2}$ formation reactions. Stability of these molecules of these compounds and their Gibbs free energies of formation (assuming large residence times and possibility of reaching equilibrium) can play an important role, as well. On the contrary, increasing the coal flow rate increases $\mathrm{SO}_{2}$ while decreasing the $\mathrm{NO}_{2}$ concentration (Figure 5B). We also note that the concentration of NO was high in the model $(\sim 16112 \mathrm{ppm})$, and this is consistent with both the experiments and literature. It should be noted that future work will be focused on further developing the model to include coal attrition and particle characteristics, along with kinetic modeling of other components including, tar.

Lastly, the effect of pressure of the secondary inlet air flow rate was analyzed. The convergence issues occurred when secondary air stream was set to values below 2 bars. Therefore, the pressure was set to 2 bars for modelling in HTZONE unit for standard case. According to sensitivity analysis presented in Figure 6, the conversion is affected notably by the change of the pressure, particularly due to the kinetics and high mole fractions. Moreover, it can be inferred that increasing pressure favors combustion up to 5 bars and plateaus beyond.

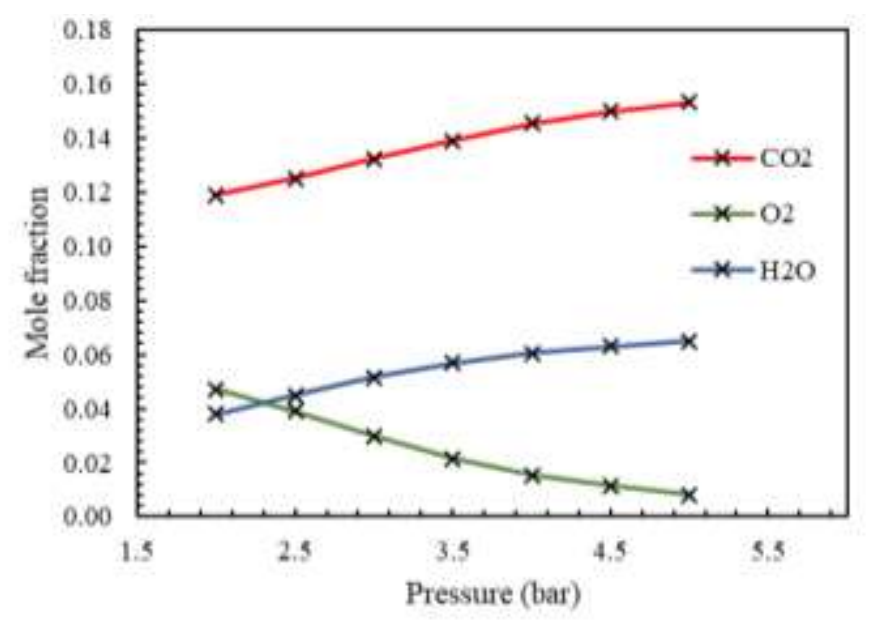

Figure 6: Effect of secondary air inlet pressure on the mole fraction of flue gases. 


\section{CONCLUSIONS}

An innovative hybrid model has been developed in Aspen Plus for coal combustion in circulating fluidized beds as a combination of conventional reactor models (RSTOIC, RGIBBS, RYILED) and the newly-introduced FLUIDBED offering the competitive advantages of both new and old simulation models in the literature. The core process synthesis and development were performed so that the simulation can be readily extended to hierarchal models for larger process flow diagrams representing more complicated pretreatment/solid handling, air preheat, cyclone separation and recirculation, post-treatment of flue gases. The kinetics-based nature of the approach chosen enables a wide range of engineering research activities such as conceptual design, sizing, scale-up, technical economic and environmental impact assessments. The proposed model is capable of future expansion and deemed not to be a case-specific model and is flexible in terms of the types of feedstock (coal, biomass etc.). Finally, it adopts a modifiedequilibrium approach for $\mathrm{NO}_{\mathrm{x}} \& \mathrm{SO}_{\mathrm{x}}$, determinations and a purely kinetics-based calculation for the major combustion products $\left(\mathrm{CO}, \mathrm{CO}_{2}\right.$, and $\left.\mathrm{H}_{2} \mathrm{O}\right)$ and was calibrated, fine-tuned and validated by using experimental data from a pilot-scale reactor with lignite coal as fuel.

\section{ACKNOWLEDGEMENTS}

The authors gratefully acknowledge the support provided by Nazarbayev University under the project number SOE2019011 (Project name: Co-firing of coal and biomass under air and oxyfuel environment in fluidized bed rig: Experiments with process model development) and ORAU project (contract no: 3-2020/003-2020): "Development of MSW combustion and incineration technology for Astana (Kazakhstan) and investigation of MSW blending effects on reactivity of coals in CFB combustion and gasification process" for operating the pilot-scale circulating fluidized bed reactor and for the computational resources. 


\section{REFERENCES}

[1] "IEO (International Energy Outlook)," U.S. Energy Inf. Adm. EIA Indep. Stat. Anal., 2019.

[2] C. R. Ward, "Introduction to Applied Coal Petrology," Appl. Coal Petrol., pp. 1-18, 2008.

[3] “Information, IEA Coal, Coal mining,” World Coal Association, 2019.

[4] A. Askarova, S. Bolegenova, S. Bolegenova, M. Beketayeva, V. Maximov, A. Nugymanova, and P. Šafař́ík, "Simulation of low-grade coal combustion in real chambers of energy objects," Acta Polytech., vol. 59, pp. 98-108, 2019.

[5] M. Oprisan, "Prospects for coal and clean coal technologies in Kazakhstan," IEA Clean Coal Centre, 2011.

[6] Y. Sarbassov, A. Kerimray, D. Tokmurzin, G. Tosato, and R. De Miglio, "Electricity and heating system in Kazakhstan: Exploring energy efficiency improvement paths," Energy Policy, vol. 60, pp. 431-444, 2013.

[7] C. Chen, L. Zhao, X. Wu, and J. Wang, "Numerical and experimental study on oxy-fuel coal and biomass co-firing in a bubbling fluidized bed," Energy \& Fuels, vol. 33, no. 7, pp. 5829-5839, 2019.

[8] F. El-Mahallawy and S. E-Din Habik, Fundamentals \& Technology of Combustion, 1st ed. Elsevier, 2002.

[9] W. Bian, X. Chen, and J. Wang, "A critical comparison of two-fluid model, discrete particle method and direct numerical simulation for modeling dense gas-solid flow of rough spheres," Chem. Eng. Sci., vol. 210, p. 115233, 2019.

[10] S. Pielsticker, K. Schlögel, T. Kreitzberg, O. Hatzfeld, and R. Kneer, "Biomass pyrolysis kinetics in a fluidized bed reactor: Measurements and plausibility verification for reaction conditions," Fuel, vol. 254, p. 115589, 2019.

[11] X. Wei and J. Zhu, "Capturing the instantaneous flow structure in gas-solid circulating fluidized bed using high-speed imaging and fiber optic sensing," Chem. Eng. Sci., vol. 207, pp. 713-724, 2019.

[12] A. Zylka, J. Krzywanski, T. Czakiert, K. Idziak, M. Sosnowski, K. Grabowska, T. Prauzner, and W. Nowak, "The 4th Generation of CeSFaMB in numerical simulations for CuO-based oxygen carrier in CLC system," Fuel, vol. 255, p. 115776, 2019.

[13] X. Wang, X. Liu, Y. Zhang, B. Zhang, and B. Jin, "Numerical investigation of solid-fueled chemical looping combustion process utilizing char for carbon capture," Processes, vol. 7, p. $603,2019$.

[14] Z. Dong, C. Dong, J. Zhang, and Y. Yang, "Modeling the combustion of coal in a 300mw circulating fluidized bed boiler with aspen plus," in 2010 Asia-Pacific Power and Energy Engineering Conference, 2010, pp. 1-4.

[15] X. Chen, J. Ma, X. Tian, J. Wan, and H. Zhao, "CPFD simulation and optimization of a 50 $\mathrm{kWth}$ dual circulating fluidized bed reactor for chemical looping combustion of coal," Int. J. Greenh. Gas Control, vol. 90, p. 102800, 2019.

[16] M. B. Nikoo and N. Mahinpey, "Simulation of biomass gasification in fluidized bed reactor using ASPEN PLUS," Biomass and Bioenergy, vol. 32, no. 12, pp. 1245-1254, 
2008.

[17] R. P. Nayak and R. K. Mewada, "Simulation of Coal Gasification Process using ASPEN PLUS," Proc. Int. Conf. on Current Trends in Technology: Nuicone., 2011.

[18] N. Jurado, H. G. Darabkhani, E. J. Anthony, and J. E. Oakey, “Oxy-combustion studies into the co -firing of coal and biomass blends: effects on heat transfer, gas and ash compositions," Energy Procedia, vol. 63, pp. 440-452, 2014.

[19] J. H. Pauls, N. Mahinpey, and E. Mostafavi, "Simulation of air-steam gasification of woody biomass in a bubbling fluidized bed using Aspen Plus: A comprehensive model including pyrolysis, hydrodynamics and tar production," Biomass and Bioenergy, vol. 95, pp. 157-166, 2016.

[20] "ASTM-D3172 | Standard Practice for Proximate Analysis of Coal and Coke | Document Center, Inc.," ASTM International, West Conshohocken, PA. 2013.

[21] S. George and J. Grace, "Entrainment of particles from aggregative fluidized beds." In AIChE Symp. Series 74, Fluidization, vol. 176, pp. 67-74. 1978.

[22] $\mathrm{C}$. Wen and $\mathrm{Y}$. Yu, "A generalized method for predicting the minimum fluidization velocity". AIChE Journal, vol. 12(3), pp. 610-612, 1966.

[23] S. Tasirin and D. Geldart, "Entrainment of FCC from fluidized beds - a new correlation for the elutriation rate constants $\mathrm{K}_{\mathrm{i} \text { " }}$. Powder Technology, vol. 95(3), pp. 240-247, 1998.

[24] A. Aghaalikhani, J. Schmid, D. Borello, J. Fuchs, F. Benedikt, H. Hofbauer, F. Rispoli, U. Henriksen, Z. Sárossy, and L. Cedola. "Detailed modelling of biomass steam gasification in a dual fluidized bed gasifier with temperature variation." Renew. Energy, vol. 143, pp. 703-718, 2019.

[25] D. M. Snider, S. M. Clark, and P. J. O'Rourke, "Eulerian-Lagrangian method for threedimensional thermal reacting flow with application to coal gasifiers," Chem. Eng. Sci., vol. 66, no. 6, pp. 1285-1295, 2011.

[26] H. Yoon, J. Wei, and M. M. Denn, "A model for moving-bed coal gasification reactors," AIChE J., vol. 24, no. 5, pp. 885-903, 1978.

[27] P. Kaushal, T. Pröll, and H. Hofbauer, "Model development and validation: Cocombustion of residual char, gases and volatile fuels in the fast fluidized combustion chamber of a dual fluidized bed biomass gasifier," Fuel, vol. 86, no. 17, pp. 2687-2695, 2007.

[28] F. Dryer and I. Glassman, "High-temperature oxidation of $\mathrm{CO}$ and $\mathrm{CH}_{4}$. Fourteenth international symposium on combustion," Combust. Inst. Pittsburgh, no. PA, pp. 9871003, 1973.

[29] T. Vilienskii and D. Hezmalian, "Dynamics of the combustion of pulverized fuel," Energiya, 1978.

[30] R. S. Schechter, "Transport Phenomena (Bird, R. Byron; Stewart, Warren E.; Lightfoot, Edwin N.)," J. Chem. Educ., vol. 38, no. 9, p. A640, 1961.

[31] D. Kunii and O. Levenspiel, "Fluidized reactor models. 1. For bubbling beds of fine, intermediate, and large particles. 2. For the lean phase: freeboard and fast fluidization," Ind. Eng. Chem. Res., vol. 29, no. 7, pp. 1226-1234, 1990. 
[32] F. Normann, K. Andersson, B. Leckner, and F. Johnsson, "Emission control of nitrogen oxides in the oxy-fuel process," Progress in Energy and Combustion Science, vol. 35, no. 5. pp. 385-397, 2009.

[33] R. Stanger and T. Wall, "Sulphur impacts during pulverised coal combustion in oxy-fuel technology for carbon capture and storage," Progress in Energy and Combustion Science, vol. 27, pp. 69-88, 2011.

[34] L. Xu, L. Cheng, J. Ji, Q. Wang, and M. Fang, "A comprehensive CFD combustion model for supercritical CFB boilers," Particuology. vol. 43, pp. 29-27, 2019.

[35] Y. Tan, E. Croiset, M. A. Douglas, and K. V. Thambimuthu, "Combustion characteristics of coal in a mixture of oxygen and recycled flue gas," Fuel, vol. 85, no. 4, pp. 507-512, 2006.

[36] U. Arena, "Fluidized bed gasification," in Fluidized bed technologies for near-zero emission combustion and gasification, Woodhead Publishing Limited, 2013, pp. 765-812. 